\title{
Representação gráfica da informação no desenvolvimento do programa arquitetônico.
}

\author{
João Augusto Moreira*, Renata Maria Geraldini Beltramin, Daniel de Carvalho Moreira.
}

\begin{abstract}
Resumo
A pesquisa partiu do estudo sobre o processo de projeto e o programa arquitetônico com o objetivo de caracterizar e representar as informações durante a elaboração do programa de necessidades e, assim, entender os elementos básicos para estruturar a interface de armazenamento e representação dos dados. Em consonância com o doutorado em andamento da aluna Renata Maria Geraldini Beltramin do Programa de Pós-Graduação em Arquitetura, Tecnologia e Cidade da FEC/UNICAMP, foi estabelecido o recorte temático em programa arquitetônico de ambientes corporativos. A interface de organização e manipulação dos dados foi desenvolvida através do software FileMaker Advanced Pro. Posteriormente, os dados foram exportados no formato de planilha eletrônica para o uso de ferramentas de visualização da informação. Nessa etapa, foram identificadas as ferramentas Google Charts e Google Data Studio para a apresentação dos dados e avaliados os padrões de exemplos do Projeto DataViz para organizar a informação na etapa do programa arquitetônico de escritórios. O resultado obtido é a descrição dos formatos de dados e de visualização adequados à representação do programa arquitetônico de espaços de escritórios.
\end{abstract}

\section{Palavras-chave:}

Programa arquitetônico, Processo de Projeto, Representação gráfica.

\begin{abstract}
Introdução
O programa arquitetônico é um mecanismo organizacional da informação inerente ao desenvolvimento de um projeto de arquitetura, compreendendo um processo que deve promover a inclusão e caracterização da informação em todas as etapas do processo de projeto. O programa arquitetônico deve ter como ferramenta um sistema contínuo e flexível de registro e manipulação de dados para que a representação das informações seja acessível e clara para todos os usuários e envolvidos no processo de projeto.

A pesquisa de Iniciação Científica teve como objetivo a elaboração de uma estrutura de banco de dados de informações classificadas e categorizadas para suporte à elaboração do programa de necessidades em arquitetura de ambientes corporativos. A partir desta estrutura, a pesquisa propôs um sistema de representação gráfica da informação para apoio ao desenvolvimento de programa arquitetônico.
\end{abstract}

\section{Resultados e Discussão}

As categorias de informação em um programa arquitetônico abrangem uma variedade de escopos do projeto arquitetônico, consistindo questões gerais que originam diretrizes de programa e demandam respostas de projeto. A partir de bibliografia específica (VAN MEEL; MARTENS; VAN REE, 2014) foi possível entender quais são as atividades que devem ser consideradas durante o processo de programação e de projeto de escritórios e quais são os espaços que essas atividades necessitam.

$\mathrm{Na}$ sequência, foram definidos os parâmetros para a elaboração e caracterização prévia das informações compõem o banco de dados para o programa de espaços de escritórios. Para a organização preliminar dos dados foi utilizado o software FileMaker Advanced Pro.

Os dados estruturados no banco desenvolvido em FileMaker foram exportados no formato de planilha eletrônica para o estudo de padrões de visualização de dados, como relacionados no Projeto DataViz. A partir das soluções de visualização selecionadas foram construídos gráficos de representação de dados do programa de necessidades com as plataformas Google Data Studio e Google Charts. As demonstrações dos resultados puderam ser feitas com a tabela de espaços de escritórios desenvolvida.

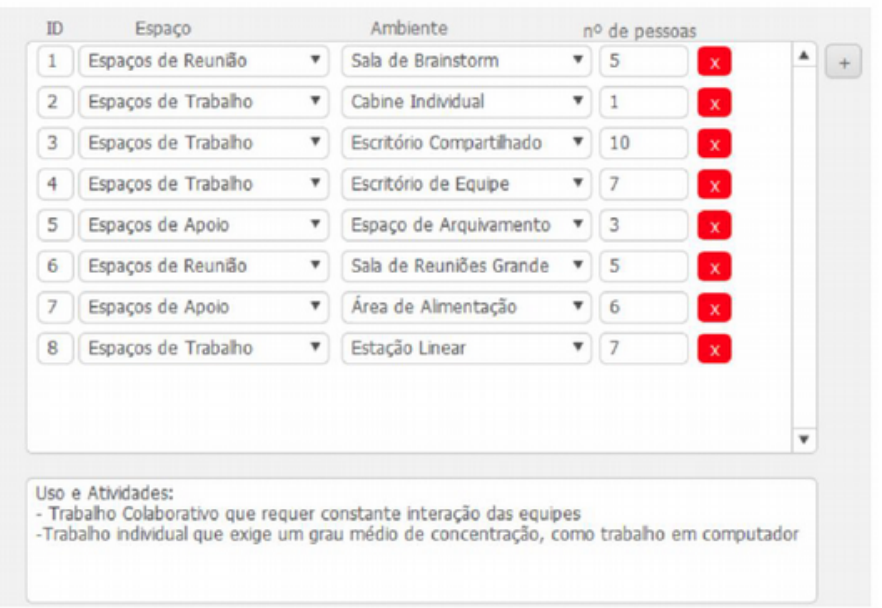

Figura 1. Interface do banco de dados.

\section{Conclusão}

A pesquisa revelou que a classificação e a organização das informações de programa de acordo com suas especificidades e impactos nas atividades previstas para o projeto possibilitam o entendimento não apenas de suas naturezas individuais como também da forma como se relacionam no contexto específico do projeto a ser desenvolvido.

A incorporação de estratégias de representação gráfica de dados à representação dessas informações de programa demonstrou que é possível apreender simultaneamente uma série de qualidades e relações de uma considerável quantidade de dados.

VAN MEEL, J.; MARTENS, Y.; VAN REE, H. J. Como planejar os espaços de escritórios: guia prático para gestores e designers. São Paulo: Gustavo Gili , 2014. 